\title{
Neurotoxicity, General Anesthesia, and the Developing Brain: What have We Learned from the Human Studies so Far?
}

\author{
Tom G. Hansen
}

Published online: 22 May 2013

(C) European Union 2013

\begin{abstract}
A multitude of animal studies have shown that virtually all general anesthetics used in clinical practice exert detrimental effects on the developing brain, notably enhanced neuroapoptosis. Some studies have also indicated that animals exposed to general anesthesia may experience long term neurobehavioral deficits later in life. The neurotoxic effects seem to be dose-dependent and have been suspected to occur at certain early developmental stages. Initially, the animal studies comprised primarily rodents but recently they have been confirmed in non-human primates. Recently, a number of (mainly retrospective) human cohort studies have been published with inconsistent results. While some studies have indicated an association between anesthesia and surgery and adverse neurobehavioral outcome, other studies have indicated no association. The cohort studies have many constraints and shortcomings. While prospective studies are underway, they will not provide any answers for several more years. The aim of this review is to provide the reader with a summary of recent human cohort studies and discuss their limitations and weaknesses. Although disturbing, the animal data lacks verification in humans. To date there are no data to support any change in clinical pediatric anesthetic practice. Any such change will be premature and potentially dangerous until we have evidence as to if and how general anesthesia impairs neurocognition and behaviour in infants and young children.
\end{abstract}

Keywords General anesthesia $\cdot$ Pediatrics . Neurotoxicity $\cdot$ Apoptosis $\cdot$ Developing brain

T. G. Hansen $(\bowtie)$

Department of Anesthesiology and Intensive Care, Odense University Hospital and University of Southern Denmark, 5000 Odense, Denmark

e-mail: tomghansen@dadlnet.dk

\section{Introduction}

Since 1999, numerous animal studies have demonstrated that exposure to most of the currently used anesthetics during a vulnerable period of brain development (i.e., brain growth spurt, peak of synaptogenesis) may lead to neurodegeneration (particularly apoptosis) and abnormal synaptic development $[1 \bullet \cdot, 2-7,8 \bullet \bullet$. Both gamma-amino butyric acid (GABA) agonists (e.g., inhalational anesthetics, propofol, benzodiazepines) and $n$-methyl- $d$ aspartate (NMDA) antagonists (e.g., ketamine and nitrous oxide) are implicated $[1 \bullet, 2-7,8 \bullet \bullet$. The observed morphological abnormalities are associated with functional deficits in learning and behaviour later in life $[8 \bullet \bullet, 9,10 \bullet]$. Initial studies were mainly performed in immature rodent pups. These investigations have been criticized for inadequate control of various physiologic parameters, supraclinical doses and duration of exposure to anesthetic drugs sometimes resulting in excessively high mortality, and for problems with translating the various developmental stages of brain development in animal models to humans $\left[10^{\bullet}, 11\right]$. Newer studies have also involved primate models and included improved physiological control during the experiments [12••, 13-15]. Notably, several hours of exposure of anesthetics were needed to result in detectable neuroapoptosis and subsequent functional deficits.

The aim of this manuscript is not to provide yet another review of the extensive animal evidence for neurotoxicity and anesthetics. Instead, following a brief summary of the critical comments made about the animal studies and a short review of normal human brain development (including normal apoptosis), this article will provide the reader with a critical review of the currently available human studies. 


\section{Limitations of Animal Data}

The majority of earlier animal investigations that described anesthetic-induced neurotoxicity were not driven by any clear or well-defined associations between general anesthesia and subsequent specific neuro-cognitive deficits in humans and the applicability to clinical care of human infants. Further, many factors exist that limit the applicability of animal-based data to humans. Specifically, differences in neurodevelopment between humans and animals may impact outcome. Factors pertaining to the administration of anesthesia and study design (such as differences in anesthetic drug potency between humans and animals, differences in monitoring and correction of physiologic aberrations in animal models, lack of surgical stimulation), use of excessively high doses of anesthetics for a long period of time, and use of agents that are rarely used in modern clinical practice (e.g. ketamine) may complicate matters. Also, the most appropriate metric to assess outcome for the presence of effects related to anesthetic-induced neurotoxicity is not clear [16, 17].

\section{Normal Development of the Human Brain}

The normal development of the human brain is a complex, continuous and a life long process. At birth, the brain is small, roughly one quarter of its adult size and uneven in maturity. Only the lower portions of the nervous system (the brain stem and the spinal cord) are well developed, whereas the higher regions (the limbic system and cerebral cortex) are still immature [18-20]. Although, all of the neurons in the cortex are produced before birth, they are poorly connected and most of their synaptic connections develop after birth during a massive burst of synapse formation - an epoch of development known as "the exuberant period" [18-21]. During this period, the maximum rate of synapse formation in the cerebral cortex is estimated to be 2 million new synapses every second. By 2 years of age, a toddler's cerebral cortex contains well over a hundred trillion synapses [21].

Myelination is the second most significant event in postnatal brain development. The brain of newborn humans contain very little myelin. Further, myelination appears to be largely "automatic or innate" such that its sequence is very predictable and severe malnutrition is the only environmental factor known to influence myelination [21].

Stimuli transmitted to the brain via sensory afferents before and after birth differentiate the function of neurons and neural pathways. This plasticity is a two edged sword. On the positive side, it means that young children's brains are more open to learning and enriching influences. Whereas on the negative side, it also means that young children's brains are more vulnerable and susceptible to environmental changes [11, 18, 21].

Pruning, or selection of active neural circuits, takes place throughout life but is far more common in early childhood. Animal studies have shown that there are certain windows of time during which the young are especially sensitive to their environment [22, 23]. Such critical periods may also hold for human development, although we are less certain about their exact length and timing.

\section{Apoptosis}

Widespread apoptosis or programmed cell death is an intimate and integral part of normal brain development. In a multicellular organism, all cells have the capacity to undergo apoptosis when needed for the benefit of the organism as a whole. Thus, apoptosis is a normal and creative aspect of multi-cellular life, including normal "maintenance". Orchestrated apoptosis helps the growing mammalian embryo to sculpt many aspects of its final form. Apoptosis is crucial to the developing human brain. Approximately half of all developing neurons fail to get enough positive reinforcement from their target neurons to avoid apoptosis [10•, 11, 24].

Apoptosis induced by anesthetics and sedatives shares many features with fetal alcohol syndrome in children [25]. Unlike fetal alcohol syndrome, in which a distinctive pattern of altered development can be grossly appreciated, any adverse effect of anesthetic exposure on young children must be small. Correspondingly, certain antiepileptic drugs (e.g., diazepam, phenytoin, phenobarbital and valproate) have also been shown to cause apoptotic neurodegeneration in the developing brain. This may suggest one mechanism to explain the cognitive impairment and reduced brain mass associated with pre- or postnatal exposure to these drugs [26].

\section{Timing of Exposure}

The timing of exposure to anesthetic drugs probably plays a role in mediating the degree of injury as the brain may have periods of increased vulnerability during different stages of development. In rats, the period of greatest vulnerability appears to occur on postnatal day 7 (PD7) and corresponds to the peak of synaptogenesis [22, 23]. In humans, the period of greatest synaptogenesis is thought to occur during the last trimester of pregnancy and up to 2 yearspostnatally. There is no data to support that the human brain is also at greatest vulnerability during this period. Further, all brain regions may not develop uniformly, thus different regions of brain may be differentially susceptible 
during different stages of development. Additionally, some of the conclusions about differential susceptibility of the brain to toxicity may be based on factors such as brain weight, water content, ganglioside, cholesterol and total DNA with hypotheses based on how these factors relate to vulnerability with respect to environmental and nutritional challenges among different animal species [27•].

A free available website has been constructed with the aim to improve accuracy in extrapolating vulnerable periods between different animal species [28]. Sadly, this new bioinformatics approach has not been applied in animal studies on anesthetic induced neurotoxicity. Studies integrating data from core developmental events from many mammalian animals into a statistical model (corrected for differences in growth rates in the cortex and the limbic system) have shown that the developmental stage of a rodent cerebral cortex at PN-7 actually corresponds to the maturational stage of the human brain at the very beginning of third trimester [29]. If this is true, animal experiments with 7-day old rodents would correlate with providing anesthetics to extremely premature babies.

\section{Relevant Outcome Measure}

A key point is: how will anesthesia related neurotoxicityif it exists-reveal itself in humans? In other words, what is a meaningful outcome measure and when and how do we measure it? Should we seek for developmental deficits in preschool, learning disabilities (LD) in elementary school, social deficits in adolescence, presence of psychiatric disorders? What relevance has loss of cognitive function in adulthood or early dementia? More importantly, how well does a short term interim measure performed in early childhood or adolescence adequately predict long term outcome? What are the long term consequences of an abnormality on a single cognitive test given at 3 years of age? What about sensory-motor deficits? At this point, currently available data cannot provide answers to these important questions $[10 \bullet, 11]$.

LD is a very crude outcome and many underlying factors may impact the learning capacity of a child, such as chronic illness and environmental influences. Further, LD is not a specific neuropsychological outcome measure, but a categorical determination based on inconsistencies between a child's educational expectations, such as intelligence quotient, and his or her actual achievement [10•, 11, 30•, 31-33].

Reporting the cumulative incidence of $L D$ requires that follow-up is stopped when LD is detected. Specifically, once a child meets the criterion for learning disabilities, it is assumed that LD persist and never resolve. This hinders estimation of the true prevalence of the outcome. It is possible that children with LD may at some point have a change in performance which puts them back in the normal range. Such an event will not be captured by the current used study designs. Assessment of academic achievements have a pragmatic advantage over intelligence quotient testing because parents are likely to be more interested in how their child will do in school rather than how they will do in a test of intelligence [34••].

Attention-deficit hyperactivity disorder (ADHD) has also been used as an independent outcome measure to assess for anesthetic-induced neurotoxicity [35]. ADHD and its diagnosis and treatment are controversial. There is a large variation in the prevalence of ADHD across countries, states, races, genders and ethnicities. Recently in United States, one in five teenage boys have been shown to be labeled with an ADHD diagnosis; two-third of whom are taking long term medications such as dexamphetamine [36•]. Additionally, ADHD is associated with a variety of psychiatric disorders and learning disabilities, limiting the appropriateness of ADHD as an outcome measure in studies on neurotoxicity and anesthesia.

\section{Human Cohort Studies}

Compared to the magnitude of animal investigations, the number of human studies is relatively limited with only 13 studies published to date (12 retrospective studies and one prospective study) [30•, 31-33, 34••, 35, 37-39, 40••, 4143] (Table 1).

The single prospective study indicated a lower than expected neurodevelopmental outcome (at 1 year of age) in infants undergoing repair of pyloric stenosis compared with healthy infants not having surgery [43]. However, the investigation only involved 43 infants who underwent surgery within the first 90 days of life. Further, developmental assessment was conducted in all subjects within the first year of life which potentially limited the complexity of metrics used to assess neurodevelopmental outcome. Other limitations included a potentially high rate of other congenital anomalies reported in the treatment group (i.e., $8 \%$ vs. rate not reported in control sample) and the potential for other factors related to pyloric stenosis (e.g., electrolyte abnormalities, dehydration) impacting neurodevelopmental outcome prior to repair. The small sample size and other confounding factors make extrapolation of these data difficult.

The Mayo Clinic group have published a series of retrospective epidemiological cohort studies based on the same birth cohort comprising 5,357 children born between 1976 and 1982 in Olmsted County Minnesota in the United States [30•, 31-33, 34••]. First, they identified 593 children who underwent surgery and anesthesia before the age of 
Table 1 A short summary of the currently available human cohort studies

\begin{tabular}{|c|c|c|c|c|c|c|c|c|}
\hline Source & Study design & $\begin{array}{l}\text { Sample size } \\
\text { exposed/non- } \\
\text { exposed }\end{array}$ & $\begin{array}{l}\text { Birth years } \\
\text { of cohort }\end{array}$ & $\begin{array}{l}\text { Age at } \\
\text { exposure }\end{array}$ & Procedures & $\begin{array}{l}\text { Outcome } \\
\text { measure }\end{array}$ & Effect(s) & Comments \\
\hline $\begin{array}{l}\text { Walker } \\
\text { et al. } \\
\text { [43] }\end{array}$ & $\begin{array}{l}\text { Prospective } \\
\text { observational } \\
\text { single center } \\
\text { cohort }\end{array}$ & $43 / 211$ & 2006-2008 & $0-1$ years & PS & BS & $\begin{array}{l}\text { Lower } \\
\text { neurodevelopmental } \\
\text { scores at age } 1 \text { years }\end{array}$ & $\begin{array}{l}\text { Small sample, } \\
\text { outcome measured } \\
\text { at age } 1 \text { years } \\
\text { Numerous } \\
\text { confounders }\end{array}$ \\
\hline $\begin{array}{l}\text { Wilder } \\
\text { et al. } \\
{\left[30^{\bullet}\right]}\end{array}$ & Birth cohort & $593 / 4,764$ & 1976-1982 & $0-4$ years & All & LD & $\begin{array}{l}2+\text { exposures } \\
\text { associated with } \\
\text { increased risk of } \mathrm{LD}\end{array}$ & $\begin{array}{l}\text { Protected cohort, } \\
\text { huge migration, } \\
\text { multiple } \\
\text { procedures, few } \\
\text { infants }\end{array}$ \\
\hline $\begin{array}{l}\text { Flick et al. } \\
\text { [31] }\end{array}$ & $\begin{array}{l}\text { Birth cohort } \\
\quad \text { (case-control) }\end{array}$ & $350 / 750$ & 1976-1982 & $0-2$ years & All & $\begin{array}{l}\text { LD, CAT, } \\
\text { TCS }\end{array}$ & $\begin{array}{l}2+\text { exposures } \\
\text { associated with } \\
\text { increased risk of LD, } \\
\text { CAT and TCS }\end{array}$ & $\begin{array}{l}\text { Protected cohort, } \\
\text { huge migration, } \\
\text { multiple } \\
\text { procedures, few } \\
\text { infants }\end{array}$ \\
\hline $\begin{array}{l}\text { Sprung } \\
\text { et al. } \\
\text { [35] }\end{array}$ & Birth cohort & $341 / 5,016$ & 1976-1982 & $0-2$ years & All & ADHD & $\begin{array}{l}2+\text { exposures } \\
\text { associated with } \\
\text { increased risk of } \\
\text { ADHD }\end{array}$ & $\begin{array}{l}\text { Protected cohort, } \\
\text { huge migration, } \\
\text { multiple } \\
\text { procedures, few } \\
\text { infants }\end{array}$ \\
\hline $\begin{array}{l}\text { Flick et al. } \\
\text { [33] }\end{array}$ & Birth cohort & $1495 / 3,189$ & 1976-1982 & At birth & $\begin{array}{l}\text { Normal } \\
\text { delivery }\end{array}$ & LD & No difference & $\begin{array}{r}\text { Protected cohort, } \\
\text { huge migration }\end{array}$ \\
\hline $\begin{array}{l}\text { Sprung } \\
\text { et al. } \\
\text { [32] }\end{array}$ & Birth cohort & $497 / 4,823$ & 1976-1982 & At birth & $\begin{array}{l}\text { Cesarian } \\
\text { delivery }\end{array}$ & LD & No difference & $\begin{array}{r}\text { Protected cohort, } \\
\text { huge migration }\end{array}$ \\
\hline $\begin{array}{l}\text { Kalkman } \\
\text { et al. } \\
\text { [37] }\end{array}$ & $\begin{array}{l}\text { Single center } \\
\text { cohort }\end{array}$ & $\begin{array}{l}\text { 243, no } \\
\text { controls, } \\
\text { comparison } \\
\text { within } \\
\text { cohort }\end{array}$ & 1987-1995 & $0-6$ years & Uro & $\begin{array}{l}\text { CBC by } \\
\text { parents }\end{array}$ & No difference & $\begin{array}{l}\text { Small sample single } \\
\text { center }\end{array}$ \\
\hline $\begin{array}{l}\text { DiMaggio } \\
\text { et al. } \\
\text { [38] }\end{array}$ & $\begin{array}{l}\text { New York State } \\
\text { Medicaid } \\
\text { payers }\end{array}$ & $383 / 5,050$ & 1999-2002 & $0-3$ years & $\mathrm{IH}$ & ICD-9 & $\begin{array}{l}\text { Increased risk for } \\
\text { developmental and } \\
\text { behavioral codes }\end{array}$ & $\begin{array}{l}\text { Cohort not } \\
\text { representative } \\
\text { classification } \\
\text { problems with } \\
\text { exposure and } \\
\text { outcome data }\end{array}$ \\
\hline $\begin{array}{l}\text { DiMaggio } \\
\text { et al. } \\
\text { [39] }\end{array}$ & $\begin{array}{l}\text { New York State } \\
\text { Medicaid } \\
\text { payers (case } \\
\text { control) }\end{array}$ & $304 / 10,146$ & 1999-2005 & $0-3$ years & All & ICD-9 & $\begin{array}{l}\text { Increased risk for } \\
\text { developmental and } \\
\text { behavioural codes }\end{array}$ & $\begin{array}{l}\text { Cohort not } \\
\text { representative } \\
\text { classification } \\
\text { problems with } \\
\text { exposure and } \\
\text { outcome data }\end{array}$ \\
\hline $\begin{array}{l}\text { Bartels } \\
\text { et al. } \\
{\left[40^{\bullet \bullet}\right]}\end{array}$ & Twin study & $384 / 759$ & 1986-1995 & $0-3$ years & All & $\begin{array}{l}\text { Academic } \\
\text { achievement }\end{array}$ & No difference & $\begin{array}{l}\text { Powerful twin study } \\
\text { design }\end{array}$ \\
\hline $\begin{array}{l}\text { Hansen } \\
\text { et al. } \\
{[34 \bullet \bullet}\end{array}$ & $\begin{array}{l}\text { Nation-wide } \\
\text { birth cohort }\end{array}$ & $2,689 / 14,575$ & 1986-1990 & $0-1$ years & $\mathrm{IH}$ & $\begin{array}{l}\text { Academic } \\
\text { achievement }\end{array}$ & No difference & $\begin{array}{l}\text { Large sample nation- } \\
\text { wide neonates and } \\
\text { infants single } \\
\text { procedure }\end{array}$ \\
\hline $\begin{array}{l}\text { Block } \\
\text { et al. } \\
\text { [41] }\end{array}$ & Single center & $\begin{array}{l}\text { 58/no controls } \\
\text { comparison } \\
\text { to "norm" }\end{array}$ & 1990-2001 & $0-1$ years & $\begin{array}{l}\text { IH, PS, } \\
\text { Orch, } \\
\text { Circ }\end{array}$ & $\begin{array}{l}\text { Academic } \\
\text { achievement }\end{array}$ & No difference & $\begin{array}{l}\text { Small sample } \\
\text { selection bias }\end{array}$ \\
\hline $\begin{array}{l}\text { Ing et al. } \\
\text { [42] }\end{array}$ & $\begin{array}{l}\text { Birth cohort in } \\
\text { Perth, WA }\end{array}$ & $321 / 2,287$ & 1989-1992 & $0-3$ years & All & $\begin{array}{l}\text { Extensive test } \\
\text { battery }\end{array}$ & $\begin{array}{l}\text { Increased risks for } \\
\text { language and } \\
\text { cognition problems }\end{array}$ & $\begin{array}{l}\text { Type } 1 \text { error? } 1 / 3 \text { had } \\
\text { i/o ear tubes }\end{array}$ \\
\hline
\end{tabular}

$A D H D$ Attention deficit/hyperactivity disorder, $B S$ Bayley scales of infant and toddler development, $C A T$ California achievement test, $C B C$ child behavior checklist, Circ circumcision, $I C D-9$ international classification of disease, 9th revision, $I H$ inguinal hernia, i/o insertion of, $L D$ learning disabilities, $P S$ pyloric stenosis, Orch orchidopexy, TCS test of cognitive skills, Uro urological 
4 years and compared these data with those derived from children who did not undergo surgery/anesthesia ( $n=4,764$ ) [30•]. Including data from the local school system and The Reading Center/Dyslexia Institute, they compared the presence of LD in the exposure group with the control group using Cox proportional regression analysis. LD was defined as a performance on standardized achievement tests below a predefined predicted score based on the child's intelligence quotient. If any of 3 different definitions used by the school district to identify disabled learning applied, LD was considered to be present and study follow-up ceased [30•]. After adjusting for gestational age at birth, sex, and birth weight, they found that a single exposure to anesthesia (and surgery) before 4 years of age was not associated with an increased risk for subsequent LD (hazard ratio $(\mathrm{HR})=1.0 ; 95 \%$ confidence interval (CI): 0.79-1.27] [30•]. Interestingly, multiple exposures to anesthetics and surgeries increased the risk for subsequent LD. With 2 anesthetics and surgeries $(n=100)$ HR was 1.59 (95\% CI: 1.06-2.37); and with 3 or more anesthetics and surgeries $(n=44)$ HR was 2.60 (95\% CI: 1.60-4.24). Furthermore, the risk for subsequent LD was associated with a greater cumulative duration of anesthesia ( $p=0.016)$. This study suffers from many limitations. The demographics of the birth cohort is somewhat "protected" and does not reflect the diversity of the overall United States population. The degree of migration of study subjects was not trivial as almost one-third of the original cohort moved and information from these individual could not be retrieved. This is important because significant differences between migrants and non-migrants of this same birth cohort have been demonstrated more than 15 years ago [44]. Thus, selection bias is likely to have occurred as families with a significantly ill child living in close proximity to the Mayo Clinic are probably less likely to migrate. Further, children with significant co-morbidities (syndromes, chronic diseases, prematurity) are more likely to suffer from both LD and to require multiple anesthesias. The authors acknowledged this fact and attempted to correct for that by adjusting for the American Society of Anesthesiologist (ASA) physical status by excluding children with ASA physical status III and IV. Even then, the association between LD and multiple anesthetics and surgeries persisted. However, other much more important confounding factors that most likely would have affected the result of the regression analysis were not accounted for during data adjustment such as family-related (e.g., maternal and paternal age, level of education and socioeconomic status) and genetic factors. The authors were unable to disentangle the effects of surgery from that of anesthesia. Additional limitations included a large age span in the study population including exposure to anesthesia up to the age of 4 years, inclusion of very few neonates and infants as $67 \%$ of children in the study group had their first anesthetic exposure after their first year of life, and the inability to distinguish between the impact of surgical and anesthetic factors on neurodevelopmental outcome. Furthermore, $90 \%$ of the children received halothane and nitrous oxide anesthesia, without monitors such as pulse oximetry and capnography which are considered to be standard monitors today. These differences in practice since 1982 limit the generalizability of these data to present clinical practice.

To reduce the influence of confounders further, the Mayo Clinic Group then studied 350 children who were exposed to anesthesia before 2 years of age were matched with 700 children who had not been exposed to anesthesia on the basis of risk factors that are known to influence the incidence of $\mathrm{LD}$ (birth weight, gender, level of maternal education, gestational age, birth date \pm 12 months) [31]. Again, multiple exposures to anesthetics and surgeries (but not to a single exposure) were associated with an increased risk of developing $\mathrm{LD}$ (HR, 2.12; $95 \%$ CI: 1.26-3.54). The Mayo Clinic group also identified an association between exposure to anaesthesia before 2 years of age and the development of ADHD [34••]. Following adjustment for the above confounders, the authors once again indicated that multiple exposures (HR, 1.95; $95 \% \mathrm{CI}$ : 1.03-3.71), but not a single exposure (HR, 1.18; $95 \% \mathrm{CI}$ : $0.79-1.77)$ to anesthesia and surgery were associated with an increased risk for ADHD [34••].

The impact of exposure to anaesthetics prenatally has also been investigated in two studies by the Mayo Clinic group $[32,33]$. Using the same cohort, they studied 5,320 children, 4,823 of whom had vaginal delivery, 197 had Cesarean delivery with general anesthesia, and 304 had Cesarean delivery via regional anesthesia [32]. Following adjustment for confounding factors (sex, birth weight, gestational age, exposure to anesthesia before 4 years of age, and maternal education) they found that fetal exposure to general anesthesia for Cesarian delivery did not increase the cumulative risk for later LD [32]. Surprisingly, however, they also found that children born via Cesarian delivery with regional anesthesia had a lower cumulative incidence of LD than those born by vaginal delivery or Cesarian delivery via general anesthesia $(\mathrm{HR}=0.64 ; 95 \%$ CI $0.44-0.92, p=0.017)$. This finding prompted the Mayo Clinic group to explore these findings further by directly comparing the association between the use of neuroaxial labour analgesia and later childhood LD in the same cohort of children delivered vaginally [33]. Of the 4,684 mothers in the cohort who delivered children vaginally, 1,495 received neuroaxial labour analgesia. After adjusting for confounders, the risk of LD was not associated with the use of neuroaxial labor analgesia (HR $=1.05,95 \% \mathrm{CI}: 0.85-1.31, p=0.63$ ).

In the Mayo Clinic studies, three different methods for determining LD were used and exclusionary factors for LD 
(e.g., sensory impairments, social-emotional difficulties, weak academic instructions, non-English proficiency, or cultural differences) were not addressed in these investigations. Additionally, being subjected to local variation, the incidence of LD may have been inconsistent in these studies.

In a cohort of children undergoing urologic surgery in the Netherlands, the Child Behavioral Checklist was used to identify behavioral disorders [37]. In this study, children anesthetized for urological procedures before the age of 2 years tended to have a higher incidence of behavioral disturbances than children in whom such procedures were performed after the age of 2 years. These differences tended to be even stronger for children younger than 6 months of age. However, this study only included 243 returned questionnaires and hence, the results were not statistically significant. In a post hoc sample size calculation, the authors concluded that $>6,000$ individuals would be required to reach statistical difference given the effect size shown in children younger than 2 years of age, and $>2,200$ individuals in children younger than 6 months of age.

DiMaggio and Sun from New York have published 2 cohort studies using the New York State Medicaid dataset $[38,39]$. In the first study, a set of 383 Medicare procedure codes related to hernia repair in children younger than 3 years of age was compared with a control set of 5,050 age- and sex-matched Medicare records not listing these procedure codes [38]. The behavioral outcome was defined as a diagnostic code for unspecified delay or behavioral disorder, mental retardation, autism, and language and speech disorder [38]. If the behavioral outcome preceded the surgery, the record was excluded. After adjusting for age, sex, race, and the presence of confounding diagnoses at birth (birth mode, low birth weight, and perinatal hypoxia), procedure codes indicating hernia repair were more than twice as likely to be associated with the behavioral outcome codes as when procedure codes for hernia repair were absent $(\mathrm{HR}=2.3 ; 95 \% \mathrm{CI}: 1.3-4.1)$ [38]. The study design did not allow for assessing the type, frequency, and duration of the anesthetic exposure. Importantly, the authors could not exclude children in the control cohort who did not have an anesthetic for procedures other than hernia repairs. Interestingly, the behavioral disorder outcome code was diagnosed 3-4 years after exposure. The primary outcome in this study was not standardized and as such it may be subjected to variation owing to differences in local practice patterns and misclassification from diagnostic coding.

The second publication by DiMaggio and Sun was a study involving siblings [39]. To reduce the impact of confounders, they constructed a retrospective cohort (a nested case control study) comprising 10,450 siblings (twins of unknown zygocity), 306 of whom had been exposed to anesthesia during a surgical procedure before age 3 years, and 10,146 of whom had not had anesthesia [39]. Of the 138 discordant pairs in which only one of the two twins was exposed to anesthesia, neither sibling of 107 pairs had International Classification of Diseases, Ninth Revision (ICD-9) diagnostic codes indicating a problem with brain development, and both siblings of 11 pairs had such ICD-9 codes subsequent to the procedure of the exposed twin [39]. Overall, when considering the entire twin sibling population, they found an increased risk for the later diagnosis of developmental and behavioural disorders in the exposure group. Overall HR was 1.6 (95 \% CI: 1.4-1.8); increasing from 1.1 (95 \% CI: 0.8-1.4) for a single exposure to 2.9 (95\% CI: 2.5-3.1) for two exposures, and to 4.0 (95 \% CI: 3.5-4.5) for three or more exposures. When focusing on twin pairs where only one twin of a pair discordant for anaesthetic exposure had a code suggesting a problem with brain function $(n=20)$, there was an even distribution of these codes between exposed $(n=9)$ and unexposed twins $(n=11)$ [39]. This finding suggests that there was no causal relationship between anaesthesia exposure and subsequent brain dysfunction; odds ratio $(\mathrm{OR})=0.9$ (95\% CI: 0.6-1.4). However, these numbers are too small to draw any definitive conclusions.

Both investigations by DiMaggio and Sun had many limitations. The authors used the administrative data obtained from a health insurance organization and ICD-9 codes to determine exposure and outcome. The diagnosis of ADHD, and development and behavioral disorders may be affected by misclassification and underreporting. Moreover, Medicaid is a health insurance program for members of the lowest socioeconomic status in New York State, a population where confounding factors such as mental illnesses and developmental delay may be more frequent, thereby reducing the generalizability of the results.

Using the Netherlands Twin Registry, Bartels et al. [40••] studied 1,143 monozygotic twin pairs with most pairs consisting of twins who were either both exposed or both not exposed to anesthesia. However, 71 twin pairs (15\%) were discordant where one twin was exposed to anesthesia while the other did not receive anesthesia during the investigation period. Anesthesia was mainly administered for surgical procedures. The authors found that exposure to anesthesia before age 3 years significantly reduced educational achievements at age 12 years and increased reports of cognitive problems assessed by teachers. However, similar to the previous investigation by DiMaggio et al. [39], there were no differences between twins when they were discordant for anesthesia exposure. This finding suggests that anesthesia exposure at an early age may be a marker for a child's vulnerability to develop later learning problems. Further, anesthesia per se does not appear to be a risk factor. This study also has some 
limitations. In particular, no details about type of surgery or anesthesia are provided. Age at exposure and duration of exposure were not reported. However, this is indeed a significant study and if these results can be replicated, they would make a convincing argument that neither anesthesia nor surgery impact the cognitive development of children.

In a nationwide, unselected, register-based, follow up study of the Danish birth cohorts from 1986 to 1990, the association between exposure to surgery and anesthesia for inguinal hernia repair in infancy and subsequent academic achievements in adolescence were investigated [34••]. The cohort comprised 2,689 children and the control group comprised a randomly selected $5 \%$ population sample of 14,575 individuals. Exposure and outcome data were collected prospectively. Overall, exposed children scored worse than un-exposed children (average test score 0.26 lower; $95 \%$ CI 0.21-0.31). After adjusting for known confounders (sex, birth weight, parental and maternal age and education), no statistically significant difference between the hernia group and the population sample could be demonstrated (difference in test score: 0.04; $95 \%$ CI: 0.09-0.01) [34••]. However, the odds ratio (OR) for test score non-attainment associated with inguinal hernia repair was 1.18 (95\% CI: 1.04-1.35). When children with other congenital malformations were excluded from the analyses, the difference in average test scores was virtually unchanged $(0.05 ; 95 \% \mathrm{CI}$ $0.00-0.11$ ), and the increased proportion of test score non-attainment within the exposure group was attenuated $(\mathrm{OR}=1.13 ; 95 \%$ CI: 0.98-1.31) [34••]. Thus, all of the above confounders more strongly affected academic achievement than surgery and anesthesia. This is despite the fact that children were $<12$ months of age at the time of surgery, and thus may be considered more sensitive to the effects of anesthesia than older children [34••]. While these results are very reassuring, deficits in more particular cognitive domains cannot be excluded. Similarly, the effects of longer duration of exposure cannot be detectable with this study design. The higher non-attainment rate among the hernia group could suggest that a small fraction of these children are developmentally disadvantaged compared with the background population, either from other diseases/conditions or from susceptibility to anesthesia/surgery, potentially on a sex-based or genetic basis [46].

In a similar but much smaller study from Iowa in the Unites States, academic achievements test scores obtained from school-age children who as infants were exposed to anesthesia and surgery (inguinal hernia repair, orchidopexy, pylorymyotomy and circumcision) did not differ from average scores from the population of Iowa [41]. However, a higher percentage of exposed children scored below the 5th percentile. The authors contacted parents of 577 children of whom 287 had available test scores; and a total of 133 children agreed to participate in the study. However, in order to reduce confounding, the authors only investigated the 58 children whose medical records showed no risk factors for CNS problems and neurobehavioral delay. Interestingly, the authors found that duration of exposure to anesthesia and surgery correlated negatively with test scores $(r=0.34, p=0.01)$. This study has many limitations, particularly the small sample size and possible selection bias as there was limited success in linking test scores with medical records as well as in contacting patients and obtaining consent for participation.

In a recent cohort study from Western Australia, the authors used an established pregnancy cohort (the Raine cohort), which included 2,608 children who had extensive neurobehavioral testing by 10 years of age using an impressive panel of various psychological tests [42]. The 321 children who were anesthetized and underwent surgery before the age of 3 years were more likely to have deficits in language and abstract reasoning compared to nonexposed children. This study may be of limited value because the authors included all types of surgeries, including cardiac and neurosurgery. Most noteworthy was that more than one-third of the cohort comprised children undergoing myringotomies-a population notoriously known to suffer from later language and learning problems (despite the fact that a myringotomy is a very quick procedure usually lasting $<15 \mathrm{~min}$ ). Further, the use of multiple tests-as in this study - carries a high risk of a Type 1 statistical error.

As mentioned above, in all of these investigations, the effects of anesthesia per se cannot be disentangled from surgery and pathology. Bias from potential unmeasured confounders is also a problem. Given the retrospective nature of these studies, subtle but important neurocognitive deficits may have been missed. As the majority of the observations were made on population-based cohorts with relatively homogenous ethnic and socioeconomic distribution, extrapolation of the results to other populations can also be questioned. Importantly, anesthesia techniques were inconsistent across investigations. In the majority of studies, the anesthetic technique used were outdated by today's standards or even unknown (e.g., types of drugs, doses, routes of administration and duration of exposure) and did not address improvements in multiparameter monitoring (e.g., pulse oximetry, capnography, hemodynamics, end-expired concentrations of inhalational anesthetics). Most of these cohort studies include many different types of surgeries and procedures, the age of the child at anesthesia exposure extended well beyond infancy, and only a small proportion of neonates and infants are included [30•, 31, 35, 37-39, 40••, 42]. In fact, only one study focused on infants $<1$ year of age and a single surgery [34••]. 


\section{Ongoing and Future Studies}

Future cohort studies should focus on neonates and infants, a single and well-defined surgery and, as suggested by many of the cohort studies sample sizes, need to be large (i.e., several thousand subjects) [34••, 37]. Also, the "right" outcome measure also needs to be defined [10•, $11]$.

There are at least two ongoing prospective studies: the Pediatric Anesthesia and Neurodevelopment Assessment study (the PANDA study), and a multi-site randomized controlled trial (RCT) comparing regional and general anesthesia for effects on neurodevelopmental outcome and apnea (the GAS study) [45, 46]. In the PANDA study, about 500 ASA 1 and 2 children scheduled for inguinal hernia repair before 3 years of age will be compared with an unexposed sibling from a retrospective data base [45]. At the age between 8 and 15 years children will be extensively assessed neurodevelopmentally. The GAS study is a RCT in which infants undergoing inguinal hernia repair before 60 weeks post-conceptual age are randomized to either general anesthesia or regional anesthesia (spinal or caudal) [46]. The follow up time is 5 years. Final analysis of these investigations will not be available for several years.

\section{Conclusion}

A single brief anesthetic exposure seems "safe" and repeated anesthetic (and surgical) exposures have consistently been associated with LD, ADHD, etc. These associations are not necessarily causal. Children who require multiple surgeries are far more likely to suffer serious underlying medical disorders that can impact neurodevelopment. Many questions remain unanswered such as the safety of specific classes of anesthetic drugs, the impact of duration of anesthetic exposure on outcome and whether certain surgeries, systemic disorders, or phenotypes predispose to anesthetic neurotoxicity. More importantly, our current understanding of differential vulnerability of the developing human brain to anesthetic neurotoxicity is limited. Further, the most potentially relevant outcome measure to detect anesthetic neurotoxicity in not known.

Very few neonates, infants and young children undergo unnecessary anesthesia and surgery. The decision to delay surgery or a diagnostic procedure should be made with a clear understanding that any real added risk of delay is being balanced against a still ambiguous and unknown risk of toxicity. Without better evidence supporting the hypothesis that current anesthesia practice is indeed associated with poor neurobehavioral outcome because of neurotoxicity, it would be very unwise to propose any change in technique. It is ethically unacceptable to subject infants to invasive procedures without the benefit of anesthesia and analgesia. Any change in clinical practice must be evidence-based rather than driven by emotions and personal opinions. There is no assurance that "the cure or change in clinical practice will not be worse than the disease". Thus, at this point, there is no need to change current clinical practice, and no need to postpone or cancel truly urgent surgeries.

Disclosures Tom G. Hansen declares he has no conflict of interest.

Compliance with Ethics Guidelines This article does not contain any studies with human or animal subjects performed by any of the authors.

\section{References}

Papers of particular interest, published recently, have been highlighted as:

- Of importance

-• Of major importance

1. •• Ikonomidou C, Bosch F, Miksa M, et al. Blockade of NMDA receptors and apoptotic neurodegeneration in the developing brain. Science. 1999;283(5398):70-74. Breakthrough paper about NMDA receptor antagonists and apoptotic neurodegeneration.

2. Yon JH, Daniel-Johnson J, Carter LB, Jevtovic-Todorovic V. Anesthesia induces neuronal cell death in the developing rat brain via the intrinsic and extrinsic apoptotic pathways. Neuroscience. 2005;135(3):815-27.

3. Lunardi N, Ori C, Erisir A, Jevtovic-Todorovic V. General anesthesia causes long-lasting disturbances in the ultrastructural properties of developing synapses in young rats. Neurotox Res. 2010;17(2):179-88.

4. Briner A, De Roo M, Dayer A, et al. Volatile anesthetics rapidly increase dendritic spine density in the rat medial prefrontal cortex during synaptogenesis. Anesthesiology. 2010;112(3):546-56.

5. Lunardi N, Hucklenbruch C, Latham JR, et al. Isoflurane impairs immature astroglia development in vitro: the role of actin cytoskeleton. J Neuropathol Exp Neurol. 2011;70(4):281-91.

6. Lemkuil BP, Head BP, Pearn ML, et al. Isoflurane neurotoxicity is mediated by p75NTR-RhoA activation and actin depolymerization. Anesthesiology. 2011;114(1):49-57.

7. Fredriksson A, Pontén E, Gordh T, Eriksson P. Neonatal exposure to a combination of $N$-methyl- $D$-aspartate and gammaaminobutyric acid type A receptor anesthetic agents potentiates apoptotic neurodegeneration and persistent behavioral deficits. Anesthesiology. 2007;107(3):427-36.

8. • Jevtovic-Todorovic V, Hartman RE, Izumi Y, et al. Early exposure to common anesthetic agents causes widespread neurodegeneration in the developing rat brain and persistent learning deficits. J Neurosci. 2003;23(3):876-882. First study to shown that anesthetic exposure causes both apoptotic neurodegeneration and long term cognitive impairment.

9. Bambrink AM, Orfanakis K, Kirsch JR. Anesthestic neurotoxicity. Anesthesiol Clin. 2012;3:207-28.

10. - Stratman G. Review article: neurotoxicity of anesthetic drugs in the developing brain. Anesth Analg. 2011;113(5):1170-1179. 
Important review paper on the topic highlighting many important limitations of the animal studies.

11. Vutkits L, Davies PJ, Hansen TG. Anesthetic and the developing brain: time for a change in practice? A pro/con debate. Pediatr Anesth. 2012;22(10):973-80.

12. • Paule MG, Li M, Allen RR, et al. Ketamine anesthesia during the first week of life can cause long-lasting cognitive deficits in rhesus monkeys. Neurotoxicol Teratol. 2011;33(2):220-230. First study to show that non human primates exposed to ketamine also display both apoptotic neurodegeneration and cognitive impairment.

13. Slikker W Jr, Zou X, Hotchkiss CE, et al. Ketamine-induced neuronal cell death in the perinatal rhesus monkey. Toxicol Sci. 2007;98:145-58.

14. Zou X, Liu F, Zhang X, et al. Inhalational anesthetic-induced neuronal damage in the developing rhesus monkey. Neurotoxicol Teratol. 2011;33:592-9.

15. Zou X, Patterson TA, Divine RL, et al. Prolonged exposure to ketamine increases neurodegeneration in the developing monkey brain. Int J Dev Neurosci. 2009;27:727-31.

16. Rappaport B, Mellon RD, Simone A, Woodcock J. Defining safe use of anesthesia in children. N Engl J Med. 2011;364(15):1387-90.

17. Glass NL, Malviya S. Anesthesia in children-limitations of the data on neurotoxicity. N Engl J Med. 2011;364(15):1466-7.

18. Sun L. Early childhood general anaesthesia exposure and neurocognitive development. Br J Anaesth. 2010;105(Suppl 1): i61-8.

19. Todd MM. Anesthetic neurotoxicity: the collision between laboratory neuroscience and clinical medicine. Anesthesiology. 2004;1001:272-3.

20. Anand KJ, Soriano SG. Anesthetic agents and the immature brain: are these toxic or therapeutic? Anesthesiology. 2004;101: 527-30.

21. Johnson MH. Functional brain development in humans. Nat Rev Neurosci. 2001;2(7):475-83.

22. De Roo M, Klauser P, Briner A, et al. Anesthetics rapidly promote synaptogenesis during a critical period of brain development. PLoS One. 2009;4(9):e7043.

23. Rizzi S, Ori C, Jevtovic-Todorovic V. Timing versus duration: determinants of anesthesia-induced developmental apoptosis in the young mammalian brain. Ann NY Acad Sci. 2010;1199: 43-51.

24. Patel P, Sun L. Update on neonatal anesthetic neurotoxicity: insight into molecular mechanisms and relevance to humans. Anesthesiology. 2009;110(4):703-8.

25. Ikonomidou $\mathrm{C}$, Bittigau $\mathrm{P}$, Ishimaru $\mathrm{MJ}$, et al. Ethanol-induced apoptotoc neurodegeneration and fetal alcohol syndrome. Science. 2000;287:1056-60.

26. Bittigau P, Sifringer M, Genz K, et al. Antiepileptic drugs and apoptotic neurodegeneration in the developing brain. Proc Natl Acad Sci USA. 2002;99(23):15089-94.

27. - Dobbing J, Sands J. Comparative aspects of the brain growth spurt. Early Hum Dev. 1979;3(1):79-83. Scholarly article often misquoted in this context.

28. Clancy B, Darlington RB, Finlay BL. Translating developmental time across mammalian species. Neuroscience. 2001;105(1):7-17.

29. Clancy B, Finlay BL, Darlington RB, et al. Extrapolating brain development from experimental species to humans. Neurotoxicology. 2007;28(5):931-7.

30. - Wilder RT, Flick RP, Sprung J, et al. Early exposure to anesthesia and learning disabilities in a population-based birth cohort.
Anesthesiology. 2009;110(4):796-804. First cohort study to indicate that repeated exposure to surgery and anesthesia is associated with learning disabilities.

31. Flick RP, Katusic SK, Colligan RC, et al. Cognitive and behavioral outcomes after early exposure to anesthesia and surgery. Pediatrics. 2011;128(5):e1053-61.

32. Sprung J, Flick RP, Wilder RT, et al. Anesthesia for cesarian delivery and learning disabilities in a population-based birthcohort. Anesthesiology. 2009;111(2):302-10.

33. Flick RP, Lee K, Hofer RE, et al. Neuraxial labor analgesia for vaginal delivery and its effect on childhood learning disabilities. Anesth Analg. 2011;112(6):1424-31.

34. • Hansen TG, Pedersen JK, Henneberg SW, et al. Academic performance in adolescence after inguinal hernia repair in infancy: a nationwide cohort study. Anesthesiology. 2011;114(5): 1076-1085. A large nation-wide cohort study $(n=2.689)$ indicating no association between exposure to anesthesia and surgery for inguinal hernia repair in infancy and academic achievements in adolescence.

35. Sprung J, Flick RP, Katusic SK, et al. Attention-deficit/hyperactivity disorder after early exposure to procedures requiring general anesthesia. Mayo Clin Proc. 2012;87(2):120-9.

36. - Visser SN, Blumberg SJ, Danielson ML, et al. State-based and demographic variation in parent-reported medication rates for attention-deficit/hyperactivity disorder, 2007-2008. Prev Chron Dis. 2013;10:20073. Important study indicating the high use of ADHD diagnosis in the USA, particularly in teenage boys.

37. Kalkman CJ, Peelen L, Moons KG, et al. Behavior and development in children and age at the time of first anesthetic exposure. Anesthesiology. 2009;110:805-12.

38. DiMaggio C, Sun LS, Kakavouli A, et al. A retrospective cohort study of the association of anesthesia and hernia repair surgery with behavioral and developmental disorders in young children. J Neurosurg Anesthesiol. 2009;21(4):286-91.

39. DiMaggio C, Sun LS, Li G. Early childhood exposure to anesthesia and risk of developmental and behavioral disorders in a sibling birth cohort. Anesth Analg. 2011;113(5):1143-51.

40. $\bullet$ Bartels M, Althoff RR, Boomsma DI. Anesthesia and cognitive performance in children: no evidence for a causal relationship. Twin Res Hum Genet. 2009;12(3):246-253. A very important twin study showing that in monozygotiv twin pair discordant for anesthetic and surgical exposure there was no increased risk for cognitive problems.

41. Block RI, Thomas JJ, Bayman EO, et al. Are anesthesia and surgery during infancy associated with altered academic performance during childhood? Anesthesiology. 2012;117(3):494-503.

42. Ing $C$, DiMaggio $C$, Whitehouse $A$, et al. Long-term differences in language and cognitive function after childhood exposure to anesthesia. Pediatrics. 2012;130(3):e476-85.

43. Walker K, Halliday R, Holland AJ, et al. Early developmental outcome of infants with infantile hypertrophic pyloric stenosis. J Pediatr Surg. 2010;45(12):2369-72.

44. Katusic SK, Colligan RC, Barbaresi WJ, Schaid DJ, Jacobson SJ. Potential influence of migration bias in birth cohort studies. Mayo Clin Proc. 1998;73:1053-61.

45. Sun LS, Li G, DiMaggio CJ, et al. Feasibility and pilot study of the pediatric anesthesia neurodevelopment assessment (PANDA) project. J Neurosurg Anesthesiol. 2012;24(4):382-8.

46. Davidson AJ, McCann ME, Morton NS, Myles PS. Anesthesia and outcome after neonatal surgery: the role for randomized trials. Anesthesiology. 2008;109(6):941-4. 